\title{
Finding Use for Sorghum Bicolor Leaf Sheath in Coating Technology
}

\author{
Johnson Ajeh Isaac ${ }^{1, *}$ Kayode llesanmi Fasuba ${ }^{1}$ \\ ${ }^{1}$ Department of Pharmaceutical Technology and Raw Materials \\ Development, National Institute for Pharmaceutical Research and \\ Development (NIPRD), Abuja, Nigeria \\ Pharmaceut Fronts 2021;3:e119-e128.

\begin{abstract}
Address for correspondence Johnson Ajeh Isaac, PhD, Department of Pharmaceutical Technology and Raw Materials Development, National Institute for Pharmaceutical Research and Development (NIPRD), Plot 942, Cadastral Zone C16, Idu Industrial District 1B, P.M.B 21, Garki, Abuja 900104, Nigeria (e-mail: ajeh.johnson@niprd.gov.ng).
\end{abstract}
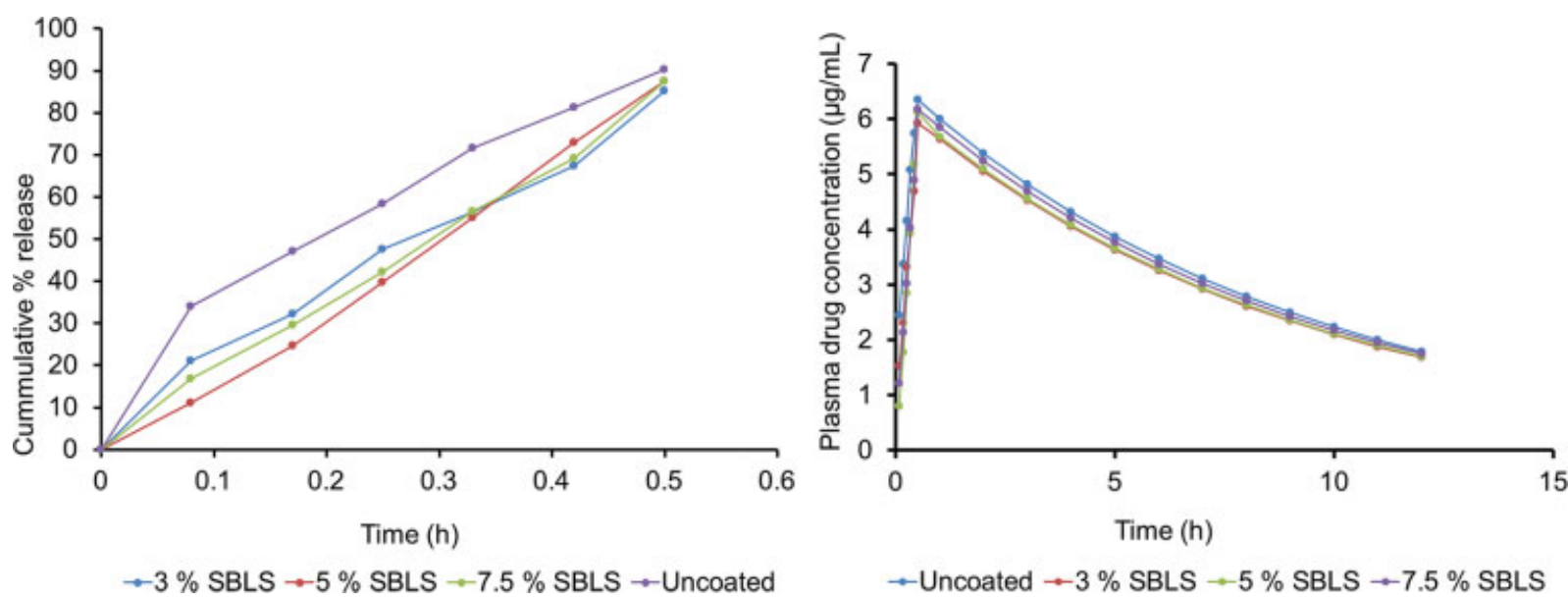

\section{Abstract \\ Keywords \\ - Sorghum bicolor leaf sheath \\ - coat agent \\ - paracetamol tablet \\ - in vitro-in vivo correlation}

This study aimed to investigate the potential use of aqueous extract of Sorghum bicolor leaf sheath (SBLS) as a coating agent for paracetamol tablets. The mechanical properties of the coated tablets were assessed using crushing strength and friability test, while the release properties of the tablet were evaluated using disintegration and dissolution tests. The physicochemical properties of the coated tablets did not show any striking differences when compared with the uncoated tablet as par compendium specifications, which formed the basis for performing further in vitro dissolution study. Our data showed that SBLS enhanced the hardness and friability of the tablets in a dosedependent manner. Tablets coated with 3, 5, and 7.5\% of SBLS disintegrated in 8.13, 6.25 , and 4.13 minutes, respectively, while the uncoated tablet disintegrated in 0.7 minutes. Furthermore, 3, 5, and $7.5 \%$ of SBLS-coated tablets exhibited slower release of their active ingredient (releasing 21,16 , and $17 \%$, respectively) than that of the uncoated tablet (releasing $40 \%$ ) in 5 minutes. Besides, comparison between the dissolution profiles was successfully achieved using difference factor $(f 1)$ and similarity received

June 21, 2021

accepted

August 26, 2021
DOI https://doi.org/

10.1055/s-0041-1736235.

ISSN 2628-5088. (c) 2021. The Author(s).

This is an open access article published by Thieme under the terms of the Creative Commons Attribution License, permitting unrestricted use, distribution, and reproduction so long as the original work is properly cited. (https://creativecommons.org/licenses/by/4.0/)

Georg Thieme Verlag KG, Rüdigerstraße 14, 70469 Stuttgart,

Germany 
factor ( $f 2)$. The apparent dissimilarity between our coated tablets and the uncoated one led to further study of convolution in vitro-in vivo correlation, with the aim to obtain data that converted into mathematical prediction of in vivo data. For all batches, the percent predictable errors of $C_{\max }$ and $T_{\max }$ were within the acceptable limit of no more than $10 \%$. In summary, SBLS aqueous extract is a potential and protective coat agent for paracetamol tablets. The in vitro established dissolution of the coated tablets provided scientific information for the prediction of the in vivo plasma drug profile.

\section{Introduction}

History favored Ethiopia as where sorghum originated. It was then transported throughout Africa and through trade routes to the Middle East and India, from where it was carried to Asia along the silk route and introduced to Americas by the slave trade. ${ }^{1}$ It is believed to have been in cultivation since 5000 BCE. Sorghum is the fifth most populous grain after rice, wheat, maize, and barley, and is believed to be a source of cereal to over 300 million people globally. ${ }^{2}$ They grow well in arid and clay soil with low production cost and large potential farming area.

Sorghum bicolor (L.) Moench, one of the species of sorghum plant found in West Africa, is cultivated mainly for grain and as a fodder plant for pasture. ${ }^{3}$ It differs from other species of $S$. bicolor in their intense dark brown pigmentation. Every part of the plant, from the stalk, to the leaves, and to the seed, can be useful. In Nigeria, the fermented grain serves as a weaning food for babies. ${ }^{2}$ Leaf sheath and its extract have a wide range of bioactivities, such as antimalarial, anthelminthic, anti-inflammatory, antioxidant, immune booster, hepatoprotective, hematopoietic, nutritional supplement, and insecticide, and acts as a therapy for managing anemia, sickle cell disease, and human immunodeficiency virus. ${ }^{1}$ Aside its medicinal use, the intense dark brown color extracted from the leaf sheath is used to dye basket, goat skins, textiles, grass mats, wool, mud houses, and as body paint. ${ }^{1}$ It is also used in potteries as a binder in the northern part of Nigeria. S. bicolor leaf sheath (SBLS) is $22 \%$ cellulose fiber, and is an agricultural waste that is available all year round. It is nontoxic, odorless, and tasteless. Its unique color could enhance pharmaceutical elegance of a tablet, and its binding ability may control drug release. However, whether and how SBLS acted as a coating agent remained largely unknown.

Paracetamol is a nonsteroidal analgesic without any antiinflammatory property. It has been on the list of World Health Organization's essential drugs since 1991, and a preferred drug of choice to persons who will not take aspirin or other nonsteroidal anti-inflammatory drugs. ${ }^{4}$ The pharmacokinetic properties of this drug have been studied extensively, but the information about its in vivo-in vitro correlation is scanty and controversial. ${ }^{5}$ It is believed that absorption of paracetamol from oral tablet preparations limits the dissolution rate of the drug. United States Pharmacopeia (USP) dissolution test for paracetamol tablets was also failed because of some formulations that are bioequiva- lent. Two controlled-released preparations that differ in release profiles of paracetamol may show different plasma concentration profiles, ${ }^{5}$ thus, developing a novel and efficient strategy to calculate the dissolution of paracetamol tablets to predict the in vivo plasma drug profile remained significantly important.

Coating is a process of applying an essentially dry and outer layer of coating materials on the surface of a dosage form to achieve a specific aim. ${ }^{6}$ Formulating paracetamol tablets could be problematic because it exhibits elastic deformation on compression-predisposing it to capping. ${ }^{4}$ By coating paracetamol, we may correct this defect. Besides, sequential release of paracetamol will also reduce dosing frequency. In this study, SBLS aqueous extract was first used as a coating agent for paracetamol tablet preparation. SBLS increased the hardness and friability of the tablets, while slowed down the drug release.

It is well known that the process of getting drug profiles from dissolution results is referred to as convolution, while extracting dissolution profile from a blood profile is called deconvolution. ${ }^{7}$ The convolution technique, though not a very popular in vitro-in vivo correlation (IVIVC) method, is preferred over the deconvolution method, because it does not require human study, and there is no need to define experimental conditions of an appropriate dissolution test for multiple products with different in vivo release properties. $^{8}$ Then, we utilized a mathematical concept, and the convolution IVIVC technique to reveal the relationship between drug release extent of the coated tablets and their amount of drug absorbed. Our data provided the promising use of SBLS aqueous extract as a coat agent for paracetamol tablet preparation in the near future.

\section{Materials and Methods}

Dried SBLSs were collected from the National Institute for Pharmaceutical Research and Development botanical garden. The leaf sheaths were cleaned from dust and other contaminants, dried in air, and then pulverized and stored in a desiccator for further use. Paracetamol tablets $500 \mathrm{mg}$ (manufactured by May \& Baker, Nigeria) were purchased from a retail pharmacy outlet in Abuja, Nigeria. All other reagents used were of analytical grades.

\section{Organoleptic Properties of SBLS Powder}

The pulverized SBLS powder was evaluated for its color, odor, taste, and texture. 


\section{Physicochemical Properties of SBLS Powder}

\section{pH Assay for SBLS Powder}

A $1 \%(\mathrm{w} / \mathrm{v})$ dispersion of the powdered sample in distilled water was allowed to stand for 1 hour at $25^{\circ} \mathrm{C}$, after which it was filtered using a $0.45 \mu \mathrm{m}$ Whatman filter paper. The $\mathrm{pH}$ of the filtrate was determined using a Mettler Toledo $\mathrm{pH}$ meter (Type 8603, Switzerland). Buffers 4, 7, and 10 were used for calibration. The electrode of the $\mathrm{pH}$ meter was placed directly into the beaker containing the solution, and was allowed to run until a constant reading was achieved.

\section{Particle Size Evaluation}

The particle size of the pulverized powder was evaluated by sieving the powder in a Reitsch test shaker (Type AS 200 control "g" GMBH, Germany). Sieves were arranged in a decreasing order of aperture. A $60 \mathrm{~g}$ of the powder was transferred on the topmost screen; the sieves were shaken for 5 minutes at an amplitude of $1,500 \mathrm{~mm} / \mathrm{g}$. The powder weight retained on each sieve was recorded. ${ }^{9}$ Percentage cumulative weight was plotted against the sieve aperture.

\section{Angle of Repose and Flow-Rate Determination}

The fixed funnel and free-standing cone method was used to identify the angle of repose. A funnel was clamped with its tip $2 \mathrm{~cm}$ over a plain paper placed on a flat surface. A $20 \mathrm{~g}$ of the powder was allowed to flow through the funnel, and the time taken for the sample to flow through the orifice of the funnel was recorded as the flow rate. ${ }^{9}$ The height $(h)$ and the radius $(r)$ of the heap were determined and the angle of repose $(\boldsymbol{\theta})$ was evaluated using Eq. (1):

$$
\theta=\tan ^{-1} h / r
$$

\section{Bulk and Tapped Densities}

The bulk and tapped densities were determined with the aid of a stampfvolumeter (STAV 2003 Jel Karl Kolb, West Germany). The powder $(20 \mathrm{~g})$ was transferred to a $100 \mathrm{~mL}$ graduated measuring cylinder. The volume occupied by the powder was noted as the bulk density in $\mathrm{g} / \mathrm{mL}$. The cylinder containing the powder was tapped 100 times and the final volume noted as the tapped density. ${ }^{9}$

Carr's Compressibility Index (Cl) and Hausner Ratio (hr) Determination

These were calculated using the below mathematical expressions Eqs. (2) and (3):

$$
\begin{gathered}
C I=\text { tapped density }- \text { bulk } \frac{\text { density }}{\text { tapped }} \text { density } \times 100 \\
h r=\text { tapped density } / \text { bulk density }
\end{gathered}
$$

\section{Moisture Content}

The powdered sample $(2 \mathrm{~g})$ was placed on a petri dish and then maintained in a Hot air oven (BS 6206A ArmouraTech) at $105 \pm 2{ }^{\circ} \mathrm{C}$ for 1 hour before being transferred to a desiccator to cool down, and then re-weighed. This process was repeated until a constant weight was obtained; the moisture content was calculated as Eq. (4):

$$
\% \text { moistue content }=W_{2}-W_{3} / W_{3}-W_{1}
$$

where $W_{1}$ is the initial weight of the bowl, $W_{2}$ the sample weight before drying + bowl weight, and $W_{3}$ the weight after drying + bowl weight.

\section{Identification Test for Paracetamol}

A mixture of concentrated $\mathrm{HCl}(1 \mathrm{~mL})$ and powder paracetamol tablet $(1 \mathrm{~g})$ was heated to boiling for 3 minutes. Then, $\mathrm{H}_{2} \mathrm{O}(1 \mathrm{~mL})$ was added, and the solution was cooled down in an ice bath with no precipitation formed. To speed up the oxidation process of paracetamol, potassium dichromate $\left(4.9 \mathrm{~g} / \mathrm{L}\right.$ in $\left.\mathrm{H}_{2} \mathrm{O}, 0.05 \mathrm{~mL}\right)$ was added to give a violet color which does not turn red. ${ }^{10}$

\section{Tablet-Coating Process}

Different concentrations of SBLS aqueous extract were prepared as following: (1) 3\% SBLS group: $3 \mathrm{~g}$ of SBLS powder was dispersed in $100 \mathrm{~mL}$ of distilled water. The suspension solution was shaken, placed at $25^{\circ} \mathrm{C}$ for 1 hour, and then filtered with $0.45 \mu \mathrm{m}$ Whatman filter paper to give SBLS extract; (2) 5\% SBLS group: the same as the 3\% SBLS group, except that $5 \mathrm{~g}$ of SBLS powder was dispersed in $100 \mathrm{~mL}$ of distilled water; (3) 7.5\% SBLS group: the same as the 3\% SBLS group, except that $7.5 \mathrm{~g}$ of SBLS powder was dispersed in $100 \mathrm{~mL}$ of distilled water.

\section{Tablet Evaluation}

\section{Weight Variation Evaluation}

Twenty tablets were selected at random, and individually weighed with the aid of an analytical balance (Type AB54, Mettler Toledo, Switzerland). Weight variation (WV) was calculated depending on the difference between a single tablet weight and a 20-tablet-average weight. ${ }^{11}$

\section{Crushing Strength}

Six tablets were randomly selected from each concentration. Each tablet was held between a fix jaw and moving jaw of the tester (D-6072, Erweka, Germany). By moving the screw knob, the force applied to the edge of the tablet was gradually increased until the tablet broke. The pressure required to break the tablet was recorded from the scale as the crushing strength. ${ }^{11}$

\section{Friability Test}

The initial weight of 10 tablets selected randomly from each batch $\left(W_{1}\right)$ was placed in a friabilator (Type TA, Erweka, Germany), set at 25 rpm for 4 minutes, after which the tablets were dusted and re-weighed $\left(W_{2}\right)$. The percent friability $(F)$ was calculated as Eq. (5):

$$
F=W_{1}-W_{2} / W_{1} \times 100
$$

\section{Disintegration}

A disintegration tester (Type ZT4, Erweka, Germany) was filled with $600 \mathrm{~mL}$ of $0.1 \mathrm{~N} \mathrm{HCl}$ maintained at $37 \pm 2^{\circ} \mathrm{C}$. 
Randomly, six tablets from each concentration were selected for the test. The disintegration time (Dt) was identified as how long it took for the fragments of the tablet to pass through the basket mesh to completely enter into the medium. $^{12}$

\section{Dissolution Testing}

The randomly selected tablets were placed into a singlestation dissolution apparatus (Type DT, Erweka, Germany) filled with $0.1 \mathrm{~N} \mathrm{HCl}(900 \mathrm{~mL})$ at $37 \pm 0.5^{\circ} \mathrm{C}$, and then rotated at $50 \mathrm{rpm}$ for 45 minutes. A $10 \mathrm{~mL}$ of the sample was withdrawn from the vessel at 5-minute intervals and filtered immediately using a $0.45 \mu \mathrm{m}$ Whatman filter paper. The $10 \mathrm{~mL}$ aliquot withdrawn was replaced with a $10 \mathrm{~mL}$ fresh medium. The absorbance of the sample was obtained using a Cary $60 \mathrm{UV} / \mathrm{vis}$ (Agilent Technologies) spectrophotometer at $257 \mathrm{~nm}$ to reflect the percent of the drug release. ${ }^{12}$

\section{Mathematical Expression}

Fit or similarity factor $(f 2)$ and dissimilarity factor $(f 1)$ were calculated as Eq. (6) and Eq. (7):

$$
\begin{gathered}
f 1=\frac{\left\{\sum_{t=1}^{n} R t-T t\right\}}{\left\{\sum_{t=1}^{n} R t\right\}} \times 100 \\
f 2=50 \times \log \left\{1+\frac{1}{n} \sum_{t-1}^{n}(R t-T t)^{2}\right\}^{-1 / 2} \times 100
\end{gathered}
$$

Where $R t$ is the percent dissolved product for the uncoated tablet at time point $t, T t$ the percent dissolved for test product, and $n$ the number of time points.

Amount released for paracetamol was calculated as \% released $\times 500 / 100$.

Discrete amount released within sampling interval was calculated as the amount released at time $(t 2)$-amount released at time $(t 1)$.

The predicted amount of drug at each time interval was calculated using the first-order elimination rate equation. Predicted total blood amount (mg) after absorption was calculated by adding all the predicted drug amounts for every time.

The elimination rate for every amount segment was calculated using Eq. (8):

$$
k e=(\operatorname{In} C 1-\operatorname{In} C 2 /(t 2-t 1)
$$

where $C 1$ and $C 2$ are predicted amounts of drug in blood at time $t 1$ and $t 2, K_{\mathrm{e}}$ the first order elimination rate constant.

The expected blood level profile was determined using Eqs. (9) and (10):

$$
\begin{aligned}
& \text { predicted conc. at times }= \\
& \text { predicted total blood amount } \times F / V_{d} \times \text { body wt }
\end{aligned}
$$

$\% P E=$ Observed parameter - Predicted parameter $\times$ 100/Observed parameter

where $F$ and $V_{\mathrm{d}}$ are bioavailability and volume of distribution and \% PE is percent predicted error. ${ }^{7}$

\section{Pharmacokinetic Parameters}

Pharmacokinetic values of paracetamol tablets obtained from reported works were as follows:

Bioavailability $F=0.76$; volume of distribution $V_{\mathrm{d}}=0.85$ $\mathrm{L} / \mathrm{Kg}$; elimination half-life $T_{1 / 2}=7$ hours; elimination rate constant $K_{\mathrm{e}}=0.11 \mathrm{~h}^{-1}$; peak plasma concentration $C_{\max }$ $=6.17 \mu \mathrm{g} / \mathrm{mL} ; T_{\max }=1.06$ hours; area under the curve $($ AUC $)=31.2 \mu \mathrm{gh} / \mathrm{mL}$; average body weight of an adult human $=62 \mathrm{~kg} .{ }^{4}$

\section{Results and Discussion}

\section{Organoleptic Properties of SBLS}

Organoleptic properties are intrinsic characters used to identify a product. - Table 1 shows the organoleptic properties of SBLS, which were all in agreement with established findings from reported works. ${ }^{1-3}$

\section{Physicochemical Properties of SBLS}

In this study, our data suggested that the $\mathrm{pH}$ of our extract was 6.30, which fits into an ideal $\mathrm{pH}$ for a polymer that is intended to be used in a tablet-coating technology $(\mathrm{pH}>5) .{ }^{11}$ Moisture content affects the way the powder flows and behaves during processing, and also plays a fundamental role in its physical appearance, and stability during storage. Our sample had 6\% moisture content, this is within the minimum requirement for any powder intended for pharmaceutical use. ${ }^{11}$ Angle of repose is a qualitative review of the internal friction of the particles at a low level of external loading by examining the frictional force in a loose powder, giving an insight into its ability to flow. ${ }^{13}$ The angle of repose is related to the density, surface area, the shapes of particles, and the coefficient of friction of the material. ${ }^{13}$ Our sample had an angle of repose of $29.80^{\circ}$, signifying excellent flow according to the British

Table 1 Organoleptic and powder properties of SBLS

\begin{tabular}{|l|l|}
\hline Test & Observation \\
\hline Color & Horse blood \\
\hline Odor & Odorless \\
\hline Taste & Tasteless \\
\hline Texture & Finely coarse \\
\hline Bulk density $(\mathrm{g} / \mathrm{mL})$ & $0.25 \pm 0.2$ \\
\hline Tapped density $(\mathrm{g} / \mathrm{mL})$ & $0.30 \pm 0.2$ \\
\hline Angle of repose $\left({ }^{\circ}\right)$ & $29.80 \pm 0.2$ \\
\hline Flow rate $(\mathrm{g} / \mathrm{sec})$ & $14.50 \pm 0.4$ \\
\hline Carr's index $(\%)$ & $20.54 \pm 0.1$ \\
\hline Hausner ratio & $1.26 \pm 0.1$ \\
\hline pH & $6.30 \pm 0.2$ \\
\hline Moisture content $(\%)$ & $6.00 \pm 0.1$ \\
\hline
\end{tabular}

Abbreviation: SBLS, Sorghum bicolor leaf sheath. Note: Values were expressed as mean \pm SD of 3 experiments. 


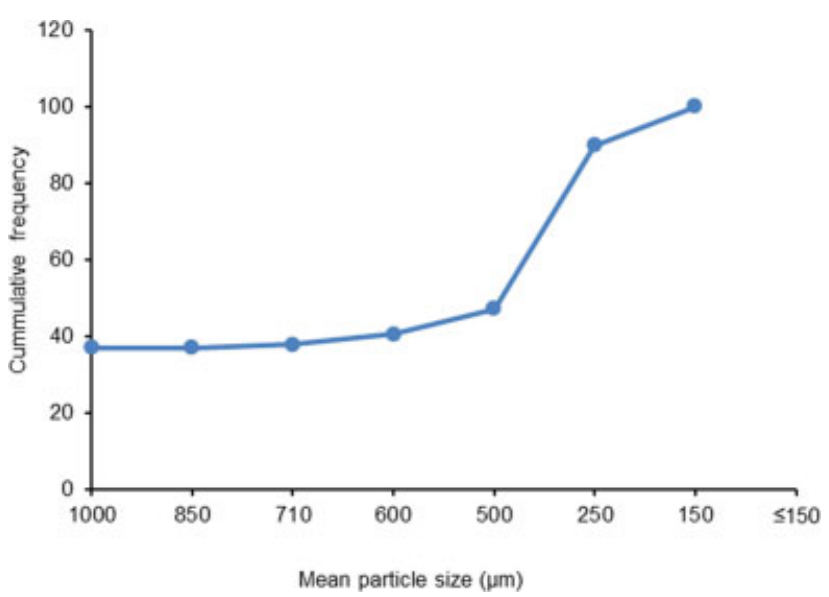

Fig. 1 Particle size analysis ( $\mu \mathrm{m})$ of SBLS powder. SBLS, Sorghum bicolor leaf sheath.

Pharmacopoeia criteria for powder flow (i.e., $\left.25^{\circ}-30^{\circ}\right) .{ }^{10}$ Flow rate evaluates the resistance to movement. When the proportion of fine particles exceeds approximately $40 \%$, there is usually a sharp fall in the flow rate. ${ }^{11}$ A high flow rate value of $14.50 \mathrm{~g} / \mathrm{s}$ observed indicated that our sample possessed low cohesive force. Hence our powder will have a good flow. The bulk and tapped densities of powder depend on the spatial arrangement of the particles in the powder bed, by undergoing rearrangement under the influence of external pressure including tapping. ${ }^{11}$ Small particles tend to fit themselves in gaps of the larger particles, and hence the total powder volume is reduced. ${ }^{11}$ Our sample had bulk and tapped densities of 0.25 and $0.30 \mathrm{~g} / \mathrm{mL}$, respectively, meaning the effect of particle rearrangement was significant. Our sample had a Carr's index value greater than $15 \%$, implying that it will not compress easily and a Hausner value greater than 1.2 , indicating that our sample is cohesive. ${ }^{11}$

Besides, more than half of SBLS powders were approximately $250 \mu \mathrm{m}$ in size (-Fig. 1), suggesting that the particles of the powders will have more cohesive force than gravitational force and are more bound together. ${ }^{9}$

\section{Tableting Properties}

A summary of the physicochemical/tableting properties of tablets coated with or without $3,5,7.5 \%$ aqueous solution of SBLS extract is presented in - Table 2. Violet color, which does not turn red on standing, confirmed the presence of paracetamol as stipulated in the paracetamol tablet monograph. ${ }^{10}$

$\mathrm{WV}$, which ensures the dosage unit, is a valuable factor in process control measurement of tablets. Compendium specification for uniformity of weight states that for tablets weighing $250 \mathrm{mg}$ or more, weights of not more than two tablets should deviate from the average weight by $5 \% .{ }^{10}$ All our tablets met this specification; however, as the concentration of our coating solution increases, so the weight of the tablets increases. This is expected due to the increase in viscosity as concentration increases.

Crushing strength, though not a compendium test, demonstrates how tablets could withstand pressure or stress during handling, manufacturing, packaging and transportation. Crushing strength ideally should account for the weight, nature, and quantity of excipients used during the process of formulation. ${ }^{5}$ Crushing strength affects friability, disintegration, dissolution, and eventually bioavailability. Conventional tablets should have a crushing strength of 4 to $10 \mathrm{kgF}^{5}$ Unfortunately, our uncoated tablets did not meet this requirement $(13.3 \mathrm{kgF})$, moreover hardness was found to be increased with the enhanced concentration of the SBLS extract. While the crushing strength tests for bulk deformation of a tablet, friability is a surface deformation that may be enhanced by the morphology of the tablet. ${ }^{9}$

Friability has a compendium specification of not more than $1 \%$. All samples did not meet this specification; however, percent friability was seen to increase as the concentration of SBLS extract increases. Type and concentration of binder and other excipients have all been implicated as factors that affect friability. ${ }^{9}$

Crushing strength-friability ratio (CSFR) measures tablet strength. The higher the value of CSFR, the stronger the tablet. $^{9}$ Our work showed that SBLS-coated tablets were much more stronger than the uncoated tablet (CSFR value: 2.08 ) with the maximum effects being seen in 5\% SBLS (CSFR value: 6.83 ).

Disintegration is used as a control for orally administered tablets; usually it is the first step toward dissolution. They act as an in-process control test to ensure lot-to-lot uniformity. ${ }^{14}$ Conventional tablets should disintegrate within 15 minutes. $^{12}$ Encouragingly, our samples met this requirement. In comparison to uncoated tablet (Dt: 0.7 minutes), SBLS-coated tablet disintegrated much more slower (Dt: 8.12, 6.25, and 4.13 at 3 , 5 , and $7.5 \%$ of SBLS, respectively)

Table 2 Tableting properties of paracetamol coated with 3, 5, and 7.5\% SBLS extract

\begin{tabular}{|l|l|l|l|l|l|l|}
\hline Batch & WV $(\mathbf{g})$ & F (\%) & CS (KgF) & CSFR & Dt (min) & CSFR/Dt \\
\hline $3 \%$ & $0.54 \pm 1.51$ & 1.42 & $6.70 \pm 1.50$ & 3.47 & $8.13 \pm 1.10$ & 0.43 \\
\hline $5 \%$ & $0.55 \pm 0.87$ & 1.93 & $9.00 \pm 0.60$ & 6.83 & $6.25 \pm 1.80$ & 1.09 \\
\hline $7.5 \%$ & $0.56 \pm 1.03$ & 2.88 & $9.70 \pm 1.00$ & 3.13 & $4.13 \pm 3.20$ & 0.76 \\
\hline Uncoated & $0.54 \pm 1.22$ & 6.40 & $13.30 \pm 1.5$ & 2.08 & $0.70 \pm 0.40$ & 2.97 \\
\hline
\end{tabular}

Abbreviations: CS, crushing strength; CSFR, crushing strength-friability ratio; Dt, disintegration time; F, friability; SBLS, Sorghum bicolor leaf sheath; WV, weight variation.

Note: Values were expressed as mean \pm SD of at least 3 experiments. 
CSFR/Dt ratio (CSFR/Dt) is a more robust index than CSFR in assessing tablet quality. It measures tablet strength, weakness, and their negative effects on Dt. The higher the CSFR/Dt, the better the balance between binder and disintegration properties. ${ }^{15}$ The uncoated batch had the highest CSFR/Dt ratio of 2.97. Our results showed that batches with the highest CSFR are not necessarily those with the highest index of CSFR/Dt.

\section{In Vitro-In Vivo Correlation Study}

The physicochemical properties for our coated tablets did not show any striking differences when compared with the uncoated paracetamol tablet. ${ }^{16}$ This formed the basis for carrying out in vitro dissolution study and further conversion of the obtained data into mathematically predicted in vivo data. The results obtained from in vitro study would give efficient and more relevant information about our coated tablet as compared with the uncoated market product.

A key aspect of the development of a product is to find in vitro characteristics of potential formulation that reflect in vivo performance. ${ }^{7}$ Dissolution test determines the rate and extent of drug absorption and subsequent therapeutic outcome. In vitro dissolution is conducted to predict assumption regarding in vivo behavior of drugs. ${ }^{8}$ Our work shows that the uncoated tablet had the fastest release, releasing approximately $40 \%$ of its drug in 5 minutes, followed by 3, 7.5, and 5\% SBLS releasing 21,16 , and $11 \%$ of its active ingredient in 5 minutes (-Fig. 2). Although all samples released up to $80 \%$ of its drug in 30 minutes as stipulated in the USP for conventional uncoated tablet, the presence of SBLS was seen to delay onset release of the drug to a certain degree. Comparison between the dissolution profiles was achieved using $f 1$, a difference factor that calculates the percent differences between the two curves at each time point, as well as $f 2$, a similarity factor that measures similarity in the percent dissolution between the two curves. Generally, $f 1$ values were up to 15 , and $f 2$ values were greater than 50 , showing sameness of the two curves. - Table 3 demonstrates

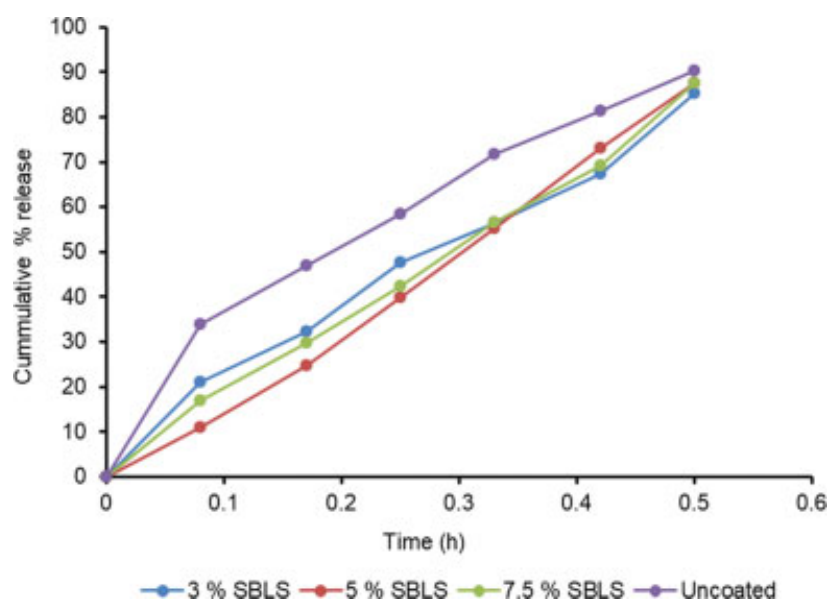

Fig. 2 Release profile of paracetamol tablets coated with 3, 5, and $7.5 \%$ SBLS extract. Values were expressed as mean \pm SD of 6 tablets. SBLS, Sorghum bicolor leaf sheath; SD, standard deviation.

Table 3 Similarity and dissimilarity values of paracetamol coated with 3,5 , and $7.5 \%$ SBLS extract

\begin{tabular}{|l|l|l|l|}
\hline & 3\% SBLS & 5\% SBLS & 7.5\% SBLS \\
\hline$f 1$ & 19 & 24 & 21 \\
\hline$f 2$ & 50 & 44 & 48 \\
\hline
\end{tabular}

Abbreviations: $f 1$, difference factor; $f 2$, similarity factor; SBLS, Sorghum bicolor leaf sheath.

the apparent dissimilarity between our coated tablets and the uncoated one, which laid the foundation for the followup IVIVC model development.

After absorption of drug, elimination stage begins, making drug release in the dissolution sampling interval to have its individual profile for first-order elimination kinetics. This profile was calculated as drug levels at different times following absorption. - Tables 4 to 7 reveal the calculated drug levels for all batches. - Fig. 3 depicts the calculated drug levels in

Table 4 Percent dissolution at different times for uncoated paracetamol tablets with corresponding amounts in mg obtained within the sampling interval

\begin{tabular}{|c|c|c|c|c|c|}
\hline \multicolumn{2}{|l|}{$T(\mathrm{~h})$} & CPR & $A R(\mathrm{mg})$ & \multicolumn{2}{|l|}{$D A R(\mathrm{mg})$} \\
\hline \multicolumn{2}{|l|}{0} & 0 & 0 & \multicolumn{2}{|l|}{0} \\
\hline \multicolumn{2}{|l|}{0.08} & 33.98 & 169.90 & \multicolumn{2}{|l|}{169.90} \\
\hline \multicolumn{2}{|l|}{0.17} & \multirow{2}{*}{$\begin{array}{l}47.08 \\
58.41\end{array}$} & 235.40 & \multicolumn{2}{|l|}{65.50} \\
\hline \multicolumn{2}{|l|}{0.25} & & 292.05 & \multicolumn{2}{|l|}{56.65} \\
\hline \multicolumn{2}{|l|}{0.33} & \multirow{2}{*}{$\begin{array}{l}71.75 \\
81.31\end{array}$} & 358.75 & \multicolumn{2}{|l|}{66.70} \\
\hline \multicolumn{2}{|l|}{0.42} & & 406.55 & \multicolumn{2}{|l|}{47.80} \\
\hline \multicolumn{2}{|l|}{0.50} & 81.31 & \multirow[t]{2}{*}{451.90} & \multicolumn{2}{|l|}{45.35} \\
\hline$T(\mathrm{~h})$ & PDA (mg) & & & PTA (mg) & $P C(\mu \mathrm{g} / \mathrm{mL})$ \\
\hline 0 & 0 & & & 0 & 0 \\
\hline 0.08 & 169.90 & & & 169.90 & 2.45 \\
\hline 0.17 & 168.23 & 65.50 & & 233.73 & 3.37 \\
\hline
\end{tabular}


Table 4 (Continued)

\begin{tabular}{|l|l|l|l|l|l|l|l|l|}
\hline$T(\mathrm{~h})$ & \multicolumn{2}{l}{ CPR } & \multicolumn{2}{l|}{ AR (mg) } & \multicolumn{2}{l|}{ DAR (mg) } \\
\hline 0.25 & 166.76 & 64.93 & 56.65 & & & 288.34 & 4.16 \\
\hline 0.33 & 165.30 & 64.36 & 56.06 & 66.70 & & & 352.42 & 5.08 \\
\hline 0.42 & 165.14 & 63.73 & 55.51 & 66.04 & 47.80 & & 398.22 & 5.74 \\
\hline 0.50 & 163.69 & 63.17 & 55.20 & 65.46 & 47.38 & 45.35 & 440.07 & 6.35 \\
\hline 1 & 154.93 & 59.79 & 55.08 & 61.96 & 44.85 & 42.92 & 416.53 & 6.01 \\
\hline 2 & 138.79 & 53.56 & 46.65 & 55.50 & 40.18 & 38.45 & 373.13 & 5.38 \\
\hline 3 & 124.33 & 47.98 & 41.79 & 49.72 & 35.99 & 34.44 & 334.25 & 4.82 \\
\hline 4 & 111.38 & 42.98 & 37.44 & 44.54 & 32.24 & 30.86 & 299.44 & 4.32 \\
\hline 5 & 99.78 & 38.51 & 33.54 & 39.90 & 28.89 & 27.46 & 268.26 & 3.87 \\
\hline 6 & 89.39 & 34.50 & 30.05 & 35.75 & 25.88 & 24.76 & 240.33 & 3.47 \\
\hline 7 & 80.08 & 30.90 & 26.92 & 32.02 & 23.18 & 22.18 & 215.28 & 3.10 \\
\hline 8 & 71.73 & 27.68 & 24.11 & 28.69 & 20.77 & 19.87 & 192.85 & 2.78 \\
\hline 9 & 64.26 & 24.80 & 21.60 & 25.70 & 18.60 & 17.80 & 172.76 & 2.49 \\
\hline 10 & 57.57 & 22.23 & 19.35 & 23.03 & 16.67 & 15.95 & 154.79 & 2.23 \\
\hline 11 & 51.57 & 19.90 & 17.33 & 20.62 & 14.93 & 14.29 & 138.64 & 2.00 \\
\hline 12 & 46.20 & 17.83 & 15.52 & 18.48 & 13.37 & 12.80 & 124.20 & 1.79 \\
\hline
\end{tabular}

Abbreviations: AR, amount release; CPR, cumulative percent release; DAR, discrete amount release within sampling interval; PBA, predicted blood amount after absorption; PC, predicted concentration at times; PTA, predicted total blood amount after absorption; T, time; TA, time after absorption.

Table 5 Percent dissolution of paracetamol tablets coated with 3\% SBLS extract at different times, and the prediction blood amount of drug after absorption within the sampling interval

\begin{tabular}{|c|c|c|c|c|c|c|c|c|}
\hline$T(\mathrm{~h})$ & $C P R$ & \multicolumn{3}{|l|}{$A R(\mathrm{mg})$} & \multicolumn{4}{|c|}{$D A R(\mathrm{mg})$} \\
\hline 0 & 0 & \multicolumn{3}{|l|}{0} & \multicolumn{4}{|l|}{0} \\
\hline 0.08 & 21.15 & \multicolumn{3}{|l|}{105.75} & \multicolumn{4}{|l|}{105.75} \\
\hline 0.17 & 32.23 & \multicolumn{3}{|l|}{161.15} & \multicolumn{4}{|l|}{55.40} \\
\hline 0.25 & 47.58 & \multicolumn{3}{|l|}{237.90} & \multicolumn{4}{|l|}{76.75} \\
\hline 0.33 & 56.39 & \multicolumn{3}{|l|}{281.95} & \multicolumn{4}{|l|}{44.05} \\
\hline 0.42 & 67.47 & \multicolumn{3}{|l|}{337.35} & \multicolumn{4}{|l|}{55.40} \\
\hline 0.50 & 85.34 & \multicolumn{3}{|l|}{426.70} & \multicolumn{4}{|l|}{89.35} \\
\hline$T A(\mathrm{~h})$ & $P B A(\mathrm{mg})$ & & & & & & PTA (mg) & $P C(\mu \mathrm{g} / \mathrm{mL})$ \\
\hline 0 & 0 & & & & & & 0 & 0 \\
\hline 0.08 & 105.75 & & & & & & 105.75 & 1.53 \\
\hline 0.17 & 104.71 & 55.40 & & & & & 160.11 & 2.31 \\
\hline 0.25 & 103.79 & 49.63 & 76.75 & & & & 230.17 & 3.32 \\
\hline 0.33 & 102.88 & 49.19 & 76.08 & 44.05 & & & 272.20 & 3.93 \\
\hline 0.42 & 101.87 & 48.71 & 75.33 & 43.66 & 55.40 & & 324.97 & 4.69 \\
\hline 0.50 & 100.98 & 48.28 & 74.67 & 43.23 & 54.91 & 89.35 & 411.42 & 5.93 \\
\hline 1 & 95.57 & 45.70 & 70.67 & 42.85 & 51.98 & 84.57 & 391.34 & 5.64 \\
\hline 2 & 85.62 & 40.94 & 63.61 & 38.39 & 46.56 & 75.76 & 350.58 & 5.06 \\
\hline 3 & 76.70 & 36.67 & 56.72 & 34.39 & 41.71 & 67.87 & 314.06 & 4.53 \\
\hline 4 & 68.71 & 32.85 & 50.81 & 30.81 & 37.37 & 60.80 & 281.35 & 4.06 \\
\hline 5 & 61.55 & 29.43 & 45.52 & 27.60 & 33.47 & 54.47 & 252.04 & 3.63 \\
\hline 6 & 55.14 & 26.37 & 40.78 & 24.73 & 29.98 & 48.79 & 225.79 & 3.26 \\
\hline
\end{tabular}


Table 5 (Continued)

\begin{tabular}{|l|l|l|l|l|l|l|l|l|}
\hline$T(\mathrm{~h})$ & CPR & \multicolumn{2}{l}{ AR $(\mathrm{mg})$} & \multicolumn{4}{l|}{ DAR (mg) } \\
\hline 7 & 49.40 & 23.62 & 36.53 & 22.15 & 26.86 & 43.71 & 202.27 & 2.92 \\
\hline 8 & 44.25 & 21.16 & 32.73 & 19.84 & 24.08 & 39.16 & 181.20 & 2.61 \\
\hline 9 & 39.64 & 18.96 & 29.32 & 17.77 & 21.56 & 35.08 & 162.33 & 2.34 \\
\hline 10 & 35.51 & 16.98 & 26.26 & 15.92 & 19.31 & 31.42 & 145.40 & 2.10 \\
\hline 11 & 31.81 & 15.21 & 23.53 & 14.26 & 17.30 & 28.15 & 130.26 & 1.88 \\
\hline 12 & 28.50 & 13.63 & 21.08 & 12.78 & 15.50 & 25.22 & 116.71 & 1.68 \\
\hline
\end{tabular}

Abbreviations: AR, amount release; CPR, cumulative percent release; DAR, discrete amount release within sampling interval; PBA, predicted blood amount after absorption; PC, predicted concentration at times; PTA, predicted total blood amount after absorption; SBLS, Sorghum bicolor leaf sheath; T, time; TA, time after absorption.

Table 6 Percent dissolution of paracetamol tablets coated with 5\% SBLS extract at different times, and the prediction blood amount of drug after absorption within the sampling interval

\begin{tabular}{|c|c|c|c|c|c|c|c|c|}
\hline$T(\mathrm{~h})$ & $C P R$ & \multicolumn{3}{|l|}{$A R(\mathrm{mg})$} & \multicolumn{4}{|c|}{$D A R(\mathrm{mg})$} \\
\hline 0 & 0 & \multicolumn{3}{|l|}{0} & \multicolumn{4}{|l|}{0} \\
\hline 0.08 & 11.08 & \multicolumn{3}{|l|}{55.40} & \multicolumn{4}{|l|}{55.40} \\
\hline 0.17 & 24.67 & \multicolumn{3}{|l|}{123.35} & \multicolumn{4}{|l|}{67.95} \\
\hline 0.25 & 39.78 & \multicolumn{3}{|l|}{198.90} & \multicolumn{4}{|l|}{75.55} \\
\hline 0.33 & 55.13 & \multicolumn{3}{|l|}{275.65} & \multicolumn{4}{|l|}{76.75} \\
\hline 0.42 & 73.01 & \multicolumn{3}{|l|}{365.05} & \multicolumn{4}{|l|}{89.40} \\
\hline 0.50 & 87.61 & \multicolumn{3}{|l|}{438.05} & \multicolumn{4}{|l|}{73.00} \\
\hline$T A(h)$ & PBA (mg) & & & & & & PTA (mg) & $P C(\mu \mathrm{g} / \mathrm{mL})$ \\
\hline 0 & 0 & & & & & & 0 & 0 \\
\hline 0.08 & 55.40 & & & & & & 55.40 & 0.80 \\
\hline 0.17 & 54.85 & 67.95 & & & & & 122.8 & 1.77 \\
\hline 0.25 & 54.37 & 67.35 & 75.55 & & & & 197.27 & 2.84 \\
\hline 0.33 & 53.89 & 66.76 & 74.89 & 76.75 & & & 272.29 & 3.93 \\
\hline 0.42 & 53.36 & 66.10 & 74.15 & 75.99 & 89.40 & & 359.00 & 5.18 \\
\hline 0.50 & 52.89 & 65.52 & 73.50 & 75.32 & 84.62 & 73.00 & 424.85 & 6.13 \\
\hline 1 & 50.06 & 62.02 & 65.84 & 71.29 & 75.80 & 69.09 & 394.10 & 5.68 \\
\hline 2 & 44.85 & 55.56 & 58.99 & 63.86 & 67.91 & 69.10 & 353.07 & 5.09 \\
\hline 3 & 40.18 & 49.77 & 52.84 & 57.21 & 60.83 & 55.45 & 316.28 & 4.56 \\
\hline 4 & 35.99 & 44.59 & 47.34 & 51.25 & 54.50 & 49.67 & 283.34 & 4.09 \\
\hline 5 & 32.24 & 39.94 & 42.41 & 45.91 & 48.82 & 44.50 & 253.82 & 3.66 \\
\hline 6 & 28.88 & 35.78 & 37.99 & 41.13 & 43.73 & 39.86 & 227.37 & 2.38 \\
\hline 7 & 25.87 & 32.05 & 34.03 & 36.85 & 39.18 & 35.71 & 203.67 & 2.94 \\
\hline 8 & 23.18 & 28.71 & 30.49 & 33.01 & 35.10 & 31.99 & 182.48 & 2.63 \\
\hline 9 & 20.76 & 25.72 & 27.31 & 29.57 & 31.44 & 28.66 & 163.46 & 2.36 \\
\hline 10 & 18.60 & 23.04 & 24.47 & 26.49 & 28.17 & 25.67 & 146.44 & 2.11 \\
\hline 11 & 16.66 & 20.64 & 21.92 & 23.73 & 25.23 & 23.00 & 131.18 & 1.89 \\
\hline 12 & 14.93 & 18.49 & 19.63 & 21.26 & 22.60 & 22.60 & 117.54 & 1.69 \\
\hline
\end{tabular}

Abbreviations: AR, amount release; CPR, cumulative percent release; DAR, discrete amount release within sampling interval; PBA, predicted blood amount after absorption; PC, predicted concentration at times; PTA, predicted total blood amount after absorption; SBLS, Sorghum bicolor leaf sheath; T, time; TA, time after absorption. 
Table 7 Percent dissolution of paracetamol tablets coated with 7.5\% SBLS extract at different times, and the prediction blood amount of drug after absorption within the sampling interval

\begin{tabular}{|c|c|c|c|c|c|c|c|c|}
\hline$T(\mathrm{~h})$ & $C P R$ & \multicolumn{3}{|c|}{$A R(\mathrm{mg})$} & \multicolumn{4}{|c|}{$D A R(\mathrm{mg})$} \\
\hline 0 & 0 & \multicolumn{3}{|l|}{0} & \multicolumn{4}{|l|}{0} \\
\hline 0.08 & 16.87 & \multicolumn{3}{|l|}{84.35} & \multicolumn{4}{|l|}{84.35} \\
\hline 0.17 & 29.71 & \multicolumn{3}{|l|}{148.55} & \multicolumn{4}{|l|}{64.20} \\
\hline 0.25 & 42.29 & \multicolumn{3}{|l|}{211.45} & \multicolumn{4}{|l|}{62.90} \\
\hline 0.33 & 56.64 & \multicolumn{3}{|l|}{283.20} & \multicolumn{4}{|l|}{71.75} \\
\hline 0.42 & 69.23 & \multicolumn{3}{|l|}{346.15} & \multicolumn{4}{|l|}{62.95} \\
\hline 0.50 & 87.61 & \multicolumn{3}{|l|}{438.05} & \multicolumn{4}{|l|}{91.90} \\
\hline$T A(\mathrm{~h})$ & PBA (mg) & & & & & & PTA (mg) & $P C(\mu \mathrm{g} / \mathrm{mL})$ \\
\hline 0 & 0 & & & & & & 0 & 0 \\
\hline 0.08 & 84.35 & & & & & & 84.31 & 1.22 \\
\hline 0.17 & 83.52 & 64.20 & & & & & 147.72 & 2.13 \\
\hline 0.25 & 82.79 & 63.64 & 62.90 & & & & 209.33 & 3.02 \\
\hline 0.33 & 82.06 & 63.08 & 62.35 & 71.51 & & & 279.24 & 4.03 \\
\hline 0.42 & 81.25 & 62.46 & 61.73 & 71.04 & 62.95 & & 339.42 & 4.90 \\
\hline 0.50 & 80.54 & 61.91 & 61.19 & 70.42 & 62.40 & 91.90 & 428.36 & 6.18 \\
\hline 1 & 76.23 & 58.60 & 57.92 & 66.65 & 59.06 & 86.98 & 405.44 & 5.85 \\
\hline 2 & 68.29 & 52.47 & 51.89 & 59.71 & 52.91 & 77.92 & 363.21 & 5.24 \\
\hline 3 & 61.18 & 47.03 & 46.48 & 53.49 & 47.40 & 69.80 & 325.38 & 4.69 \\
\hline 4 & 54.80 & 42.13 & 41.64 & 47.92 & 42.46 & 62.53 & 291.48 & 4.20 \\
\hline 5 & 49.10 & 37.74 & 37.30 & 42.92 & 38.04 & 56.20 & 261.30 & 3.77 \\
\hline 6 & 43.98 & 33.81 & 33.42 & 38.45 & 34.07 & 50.18 & 233.91 & 3.37 \\
\hline 7 & 39.40 & 30.29 & 29.94 & 34.45 & 30.52 & 44.96 & 209.56 & 3.02 \\
\hline 8 & 35.30 & 27.13 & 26.82 & 30.86 & 27.35 & 40.27 & 187.73 & 2.71 \\
\hline 9 & 31.62 & 24.31 & 24.02 & 27.64 & 24.50 & 36.08 & 168.17 & 2.43 \\
\hline 10 & 28.33 & 21.77 & 21.52 & 24.77 & 21.95 & 32.32 & 150.66 & 2.17 \\
\hline 11 & 25.38 & 19.51 & 19.28 & 22.19 & 19.66 & 28.95 & 134.97 & 1.95 \\
\hline 12 & 22.73 & 17.47 & 17.27 & 19.87 & 17.61 & 25.94 & 120.89 & 1.74 \\
\hline
\end{tabular}

Abbreviations: AR, amount release; CPR, cumulative percent release; DAR, discrete amount release within sampling interval; PBA, predicted blood amount after absorption; PC, predicted concentration at times; PTA, predicted total blood amount after absorption; SBLS, Sorghum bicolor leaf sheath; T, time; TA, time after absorption.

blood at various time intervals with the help of the pharmacokinetic parameters $\left(C_{\max }, T_{\max }\right.$, and AUC) for all batches. - Table 8 demonstrates the deduced results from the in vitro dissolution model that were mathematically converted to pharmacokinetic parameters, as well as their percent predicted errors. The percent predictable error for $C_{\max }$ and $T_{\max }$ was less than $10 \%$ (within acceptable limit), yet, greater than $20 \%$ for AUC, suggesting the lack of predictability of the model, except for those coated with 3\% SBLS extract. These findings suggested that evaluating dissolution characteristics of SBLS-coated paracetamol tablets played an important role in calculating the corresponding blood levels of this drug.

\section{Conclusion}

Aqueous extract of SBLS conferred some degree of coating on the paracetamol tablets and may require optimization for

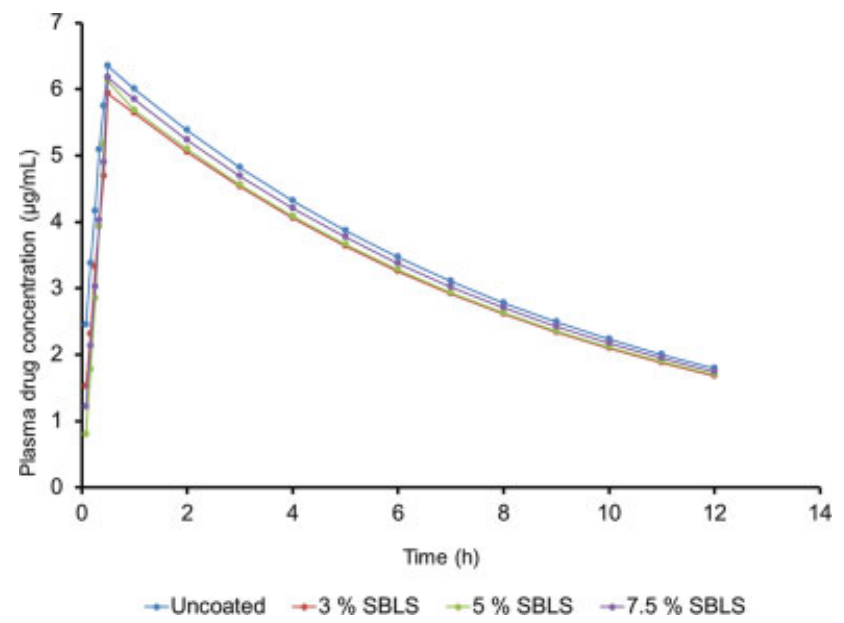

Fig. 3 Plasma drug concentration time profile derived from in vitro dissolution profiles for paracetamol tablets coated with 3, 5, 7.5\% Sorghum bicolor leaf sheath. 
Table 8 Predicted and observed pharmacokinetic parameters for paracetamol tablets coated with or without SBLS, with their corresponding percent prediction error

\begin{tabular}{|l|l|l|l|l|l|}
\hline & PV & OV (PPE) uncoated & OV (PPE) 3\% & OV (PPE) 5\% & OV (PPE) 7.5\% \\
\hline$C_{\max }$ & 6.17 & $6.35(2.83)$ & $5.93(-4.05)$ & $6.13(-0.65)$ & $6.18(0.16)$ \\
\hline$T_{\max }$ & 1.06 & $0.5(-112)$ & $0.5(-112)$ & $0.5(-112)$ & $0.5(-112)$ \\
\hline AUC & 31.2 & $43.35(28.03)$ & $38.57(19.11)$ & $40.68(23.30)$ & $41.83(25.41)$ \\
\hline
\end{tabular}

Abbreviations: AUC, area under the curve; OV, observed values; PPE, percent prediction error; PV, predicted values.

possible development. IVIVC of a drug product can be established if an in vitro dissolution test appears to be predictive of in vivo absorption. A simple convolution method that involves spread sheet software for calculating and conversion of data was employed to obtain a plasma drug concentration-time profile from in vitro dissolution data of commercially available paracetamol tablets. Our work suggested that the mathematical data derived from in vitro dissolution could give scientific information about the predicted in vivo plasma drug profile. Furthermore, pharmacokinetic data from works involving human volunteers can be employed to establish and cross-validate the model.

\section{Conflict of Interest}

The authors report no competing interest while carrying out this study.

\section{Acknowledgments}

The authors wish to express profound gratitude to $\mathrm{Mr}$. Ledou Gilama, Mr. Hassan Chamah, and Mr. Abu Garba of the National Institute for Pharmaceutical Research and Development for their technical assistance in our work.

\section{References}

1 Makanjuola S, Okubena O, Ajonuma L, Adedoyin D, Solomon U, Erah P. The west African sorghum bicolor leaf sheath extract jobelyn and its diverse therapeutic potentials. MOJ Drug Des Develop Ther 2018;2(01):20-28

2 Benson KF, Beaman JL, Ou B, Okubena A, Okubena O, Jensen GS. West African Sorghum bicolor leaf sheaths have anti-inflammatory and immune-modulating properties in vitro. J Med Food 2013;16(03):230-238

3 Rorke D, Gueguim Kana EB. Biohydrogen process development on waste sorghum (Sorghum bicolor) leaves: optimization of sac- charification, hydrogen production and preliminary scale up. Int J Hydrogen Energy 2016;41:12941-12952

4 Atebe R, Tirop LJ, Maru SM, Kuria KAM. Application of in vitro-in vivo correlation as a predictive tool for bioequivalence of generic paracetamol immediate release oral tablets. East Cent Afr J Pharm Sci 2017;20:17-26

5 Adedokun MO, Ayorinde JO, Odeniyi MA. Compressional, mechanical and release properties of a novel gum in paracetamol tablet formulation. Curr Issues Pharm Med Sci 2014;27(03):189-194

6 Ahmed S, Patil S, Khan M, Khan M. Tablet coating techniques: concept and recent trends. Int J Pharm Sci Rev Res 2021;66(01): 43-53

7 Rastogi V, Yadav P, Lal N, et al. Mathematical prediction of pharmacokinetic parameters-an in-vitro approach for investigating pharmaceutical product for IVIVC. Futur J Pharm Sci 2018; 4:175-184

$8 \mathrm{Kim} \mathrm{TH}$, Shin S, Jeong SW, Lee JB, Shin BS. Physiologically relevant in vitro-in vivo correlation (IVIVC) approach for sildenafil with site-dependent dissolution. Pharmaceutics 2019;11(06):251

9 Martins E, Christianah I, Amaka I, Olubunmi O. Effects of some channelling agents on the compaction properties of the mixed stem bark extracts of Anogeissus leiocarpus and Prosopis africana. J Herb Drugs 2017;08:9-14

10 British Pharmacopoeia. Vol I and II;London: HMSO; 2001:223$-324,1113,1523$

11 Onah JO, Bristol DO. Studies on the physico-chemical properties of starches form cajanus cajan and digitaria exilis. J Pharm Res Dev 1999;4:73-78

12 United State Pharmacopeia; USP29-NF24:21

13 Dave RH. Overview of Pharmaceutical Excipients Used in Tablets and Capsules. New York, NY: Lon Island University; 2008

14 Njega EK, Maru SM, Tirop LJ. The binder effect of povidone on the mechanical properties of paracetamol containing tablets. East Cental J Pharm Sci 2018;21:3-9

15 Adetogun GE, Alebiowu G. Properties of Delonix regia seed gum as a novel tablet binder. Acta Pol Pharm 2009;66(04):433-438

16 Holte $\emptyset$, Onsøyen E, Myrvold R, Karlsen J. Sustained release of water-soluble drug from directly compressed alginate tablets. Eur J Pharm Sci 2003;20(4-5):403-407 